\title{
Modeling Sources of Asymmetry in the Volatility of the Moroccan Dirham Exchange Rate
}

\author{
KHATTAB Ahmed ${ }^{1}, \&$ SALMI Yahya ${ }^{1}$ \\ ${ }^{1}$ Faculty of economics, Abdelmalek Essaadi University Tangier - Morocco \\ Correspondence: KHATTAB Ahmed, Faculty of economics, Abdelmalek Essaadi University Tangier - Morocco.
}

Received: May 8, 2021

Accepted: July 20, 2021

Available online: July 27, 2021

doi:10.11114/aef.v8i4.5232

URL: https://doi.org/10.11114/aef.v8i4.5232

\begin{abstract}
The main objective of this paper is to study the sources of asymmetry in the volatility of the bilateral exchange rates of the Moroccan dirham (MAD), against the EUR and the USD using the asymmetric econometric models of the ARCH-GARCH family. An empirical analysis was conducted on daily central bank data from March 2003 to March 2021, with a sample size of 4575 observations. Central bank intervention in the foreign exchange (interbank) market was found to affect the asymmetry in the volatility of the bilateral EUR/MAD and USD/MAD exchange rates. Specifically, sales of foreign exchange reserves by the monetary authority cause a fall in the exchange rate, which means that the market response to shocks is asymmetric. Finally, the selection criterion (AIC) allowed us to conclude that the asymmetric model $\mathrm{AR}(1)$-TGARCH$(1,1)$ is adequate for modeling the volatility of the exchange rate of the Moroccan dirham.
\end{abstract}

Keywords: bilateral exchange rates, TGARCH models, asymmetry, exchange rate volatility

JEL Classification: F31, F37, F47, C22, C58.

\section{Introduction}

In the current context of an international economy characterized by floating currencies and high volatility, it would be necessary to manage and reduce the volatility of the exchange rate, for this fact the central bank intervenes on the foreign exchange market, either by buying currencies against its own currency in case of appreciation of the national currency, or by selling its currencies in the opposite case (depreciation of the national currency). Despite the shift to floating exchange rates in the early 1970s, the central banks of several countries have intervened heavily in the foreign exchange market to manipulate their exchange rates and restore balance to the foreign exchange market. Indeed, Morocco has been considering a gradual shift to a more flexible exchange rate regime. But even now Morocco adopts an intermediate exchange rate regime where it is "Bank Al Maghrib" that sets the exchange rate on the basis of a fixed parity with a peg to a basket of currencies (60\% EUR, 40\% USD), so the dirham evolves in a fluctuation band of $+/-5 \%$ up and down. The central bank ensures this pegging by buying dirham when the market tends to make the rate fall and vice versa in order to maintain the exchange rate at the desired equilibrium level.

In addition, financial series have several properties that have been grouped in the theory. These include the existence of thick distribution tails (leptokurticity) and the presence of long memory in volatility. Since the studies conducted by Mandelbrot (1963) and Fama (1965), it has been well known that financial series are leptokurtic i.e., they exhibit a high kurtosis coefficient. By analyzing the effect of positive and negative shocks on this volatility, the different effects of these shocks can lead to the skewness effect. Following these considerations comes the choice of the theme of this article which consists in studying theoretically and empirically the sources of asymmetry of the volatility of the exchange rate of the Moroccan dirham, while assuming that the existence of the asymmetry in the volatility of the exchange rate is explained by the intervention of the central bank on the exchange market. This makes it important to study the effect of central bank intervention on exchange rate volatility.

In this perspective and to study the problem of the sources of asymmetry as well as the modeling of the volatility of the exchange rate in Morocco, we raised the following questions:

$\mathrm{Q}_{1}$ : What is the most appropriate asymmetric model to properly model fluctuations in the exchange rate of the Moroccan dirham? 
$\mathrm{Q}_{2}$ : What are the sources of volatility asymmetries? More precisely, is the intervention of the central bank on the exchange market the source of this asymmetry?

To answer this research questions, we developed the following hypothesis:

$\mathrm{H}_{1}$ : TGARCH Asymmetric nonlinear model is more appropriate for modeling the fluctuation of the Moroccan dirham exchange rate.

$\mathrm{H}_{2}$ : Central bank intervention in the foreign exchange market is the main source of asymmetry.

In addition, to resolve our problem, we will present the literature review, then subsequently the methodology, and finally the discussion of empirical results.

\section{Review of the Literature}

In his seminal paper, Engle (1982) developed autoregressive conditional heteroskedasticity (ARCH) processes using lagged disturbances to model volatility. The ARCH model, however, has proven through empirical studies that it requires a high ARCH order in order to meaningfully capture the dynamic behavior of volatility. The generalized ARCH model (GARCH) allowing for a more flexible lag structure was then developed by Bollerslev (1986). This model allowed for a significant reduction in the number of estimated parameters. Both ARCH and GARCH models perform well in capturing the concentration of volatility and the heaviness of financial returns, but fail in modeling leverage. This limitation of symmetric models has therefore led to the development of asymmetric models. These extensions of GARCH models include the Exponential GARCH (EGARCH) model of Nelson (1991), the Threshold GARCH of Zakoian (TGARCH) model of 1994, the Asymmetric Power ARCH (PGARCH) model of Ding and al. (1993) and the GJR model of Glosten and al. (1993). However, GARCH models also have the limitation that they cannot fully capture the leptokurtic characteristic of high-frequency financial time series. To address this problem, Bollerslev (1987), Baillie and Bollerslev (1989), and Beine and al. (2002) used the Student's t-distribution to model the innovation of the variance equation, while Nelson (1991) used the generalized error distribution (GED). The main limitation of the latter distributions is that they are symmetric and therefore do not take into account the skewness of the error distribution.

In the 1970s, following the abandonment of the fixed exchange rate regime by many countries, the monetary system was marked by a series of crises linked to exchange rate instability. Despite the transition to floating exchange rates, the central banks of several countries intervened heavily in the foreign exchange market, either by selling currencies in the event of a depreciation of the exchange rate or by buying their currencies in the opposite case (appreciation of the exchange rate) with the aim of manipulating their nominal exchange rates and thus restoring equilibrium in these markets. In this context, many researchers have tried to study the volatility of the exchange rate and verify the asymmetry of the volatility of the exchange rate in different countries of the world, where they are interested in the source of this asymmetry by examining the effect of central bank intervention on the volatility of the exchange rate.

Moreover, this research opens new doors to empirical studies that give different results. Most of these empirical studies using GARCH models argue that exchange rate volatility is asymmetric in most countries of the world. In addition to this finding, other empirical studies have investigated the source of this asymmetry by explaining it by the intervention of the central bank in the exchange market. When the domestic currency depreciates, the bank sells foreign exchange and buys its own currency. On the other hand, when the national currency appreciates, the central bank buys foreign currency against its own currency. In the first case, the conditional variance becomes larger, as well as the market reaction will increase, positive and negative shocks pose different effects on volatility. All this means that the response is asymmetric to shocks, so the intervention of the central bank in the exchange market by selling currencies is a sign asymmetry hypothesis. Thus, most researchers have reached similar conclusions, their studies strengthen the theory of asymmetry of exchange rate volatility, in contrast, other authors have a different view of the previous studies, they confirmed the non-presence of any effect of asymmetry on exchange rate volatility.

Hassan (2012) studied the exchange rate of the U.S. dollar against two major European currencies; the Euro and the British Pound, to measure any asymmetric behavior over time. He used a univariate EGRACH model to test for asymmetry in the exchange rate volatility, using daily data for the last 12 years from January 2000 to March 2012. To properly capture all possible changes in time series volatility, the data selection is based on the period immediately after the introduction of the euro by the European Union up to the current period. Other series used in the study are the pound sterling which would be useful for the main purpose of comparing currencies in the same region. The results of the exponential model (EGARCH) show that this value is negative for the British Pound and Euro series, these results clearly show that negative shocks have a greater effect on the volatility of exchange rate series than positive shocks, the author finally concluded that the volatility of exchange rate returns shows an asymmetric behavior towards positive and negative shocks where the impact of negative shocks seems to be relatively greater than the impact of any positive shock.

While Pelinescu (2014) asserts the asymmetry of exchange rate volatility by analyzing the volatility of the Romanian 
exchange rate against the euro and taking into account the influence of the volatility of other currencies. Certainly, the analysis is based on specific methods for high frequency time series. While applying the different ARCH/GARCH models on the volatility of the studied exchange rate, the results showed the existence of a strong asymmetry regarding the evolution of the exchange rate and that the exchange rate returns are correlated with the volatility.

The work of Musa and Abubakar (2014) consider that exchange rates as an important financial issue that receives global attention. They studied the volatility of the daily Dollar/Naira exchange rate using GARCH(1,1), GJR-GARCH(1,1), TGARCH(1,1), and TS-GARCH(1,1) models and daily data over the period June 1, 2000 to July 26, 2011 consisting of 4083 observations. The results of the GJR-GARCH $(1,1)$ and $\operatorname{TGARCH}(1,1)$ models show the existence of a statistically significant skewness effect.

As well as Narsoo (2015) empirically analyzed the volatility of the US dollar/Mauritian Rupee (USD/MUR) exchange rate using different GARCH, EGARCH, TGARCH, and GJR-GARCH models, while using daily data over the period of January 2004-2015. According to this empirical study, the results of the model fitting analysis show that there is evidence of the presence of volatility clustering and leverage on the exchange rate series.

Alom (2016), attempted to examine the asymmetry of the Malaysian ringgit exchange rate volatility against USD, GBP, EURO, Japanese yen, and Singapore dollar in the asymmetric component of GARCH models using daily data over the period of August 1, 2005 to April 24, 2014, while specifying the ACGARCH model (1,1). Moreover, the asymmetric effects of shocks on the volatility of Malaysian exchange rate against USD, EURO and Japanese Yen are evident, implying that positive and negative shocks pose different effects on volatility, while the symmetric effects of shocks on volatility are recorded for British Pound and Singapore dollar.

Atoi and Friday (2017), the main objective of their study is to empirically establish the level of volatility persistence and test for the presence of asymmetric effect in the three segments of the Nigerian foreign exchange market (Inter-bank Foreign Exchange Market (IFEM), exchange office (EO) and Wholesale Dutch Auction System (WDAS). The Asymmetric Threshold Generalized Autoregressive Conditional Heteroscedasticity (TGARCH) approach was adopted in the research methodology for the empirical analysis to capture the simultaneous estimation of the mean and conditional variance in 1262 sample observations. Generally, this study yielded interesting results, firstly, it reveals that the volatilities of the nominal exchange rates of the naira against the US dollar were found to be persistent in all market segments, secondly, the volatility of the interbank exchange rate is persistent and explosive, while the volatilities in the (EO) and (WDAS) market are high and moderate, respectively. This means that the (EO) segment of the Nigerian foreign exchange market is less volatile than the interbank market segment, even when the latter is more funded by foreign exchange from autonomous and official sources. Moreover, the interbank segment is more responsive to past shocks in the foreign exchange market. Finally, the study also confirms the existence of an asymmetric effect in the Nigerian foreign exchange market.

Certainly, Epaphra (2017), examined the behavior of exchange rate volatility in Tanzania, he aims to analyze time series at the daily exchange rate (TZS/USD), data between January 4, 2009 and July 27, 2015. To capture the symmetry effect in the exchange rate data. The author applies the ARCH and GARCH models. In addition, using the exponential GARCH (EGARCH) model to capture the asymmetry in the volatility clustering and the leverage effect on the exchange rate. The empirical results of this study also suggest that the behavior of the exchange rate is generally influenced by the previous information on the exchange rate. This also implies that the volatility of the previous day's exchange rate may affect the current volatility of the exchange rate. Furthermore, the asymmetric volatility estimate suggests that positive shocks imply a higher conditional variance of the next period than negative shocks of the same sign.

According to Mia and Rahman (2019), modeling exchange rate volatility can play an important role in macroeconomic management for stability and growth. His work examined the forecasting accuracy of ARCH family of models for monthly BDT/USD exchange rate data of Bangladesh Bank over the period from August 2004 to April 2019. To find an appropriate model, several model selection criteria, Akaike Information Criteria (AIC) and Schwarz Information Criteria (SIC) to measure the accuracy, Root Mean Square Error (RMSE), Mean Absolute Error (MAE), Mean Absolute Percentage Error (MAPE) and Theil's Inequality (TI) are used. Evaluation of the models using these criteria suggests that the $\operatorname{GARCH}(1,1)$ model is the best model to forecast the monthly volatility of the Bangladesh exchange rate and successfully overcome the exchange rate leverage.

Mustapha (2020) advances in his article the modeling of the phenomenon of dependence of the volatility of exchange rates in the short and long term by an approach based on the process of long memory. The empirical study had focused on a sample covering the average prices in GBP, USD and EUR during the overall period of operation of the Algerian interbank exchange rate market (March 2008 - March 2018). The results obtained testify to the presence of a certain phenomenon of long-term persistence of exchange rate volatility. FIGARCH-type processes seem to explain this phenomenon. 


\section{Data and Methodology}

This section presents the data and the approach that will be followed in this empirical study.

\subsection{Data and Variables}

In the framework of our study, we will use data of bilateral exchange rates EUR/MAD, USD/MAD as well as data of interventions of the central bank (purchases and sales of currencies) on the interbank market, to first study the volatility of the exchange rate and secondly to evaluate the effect of the intervention of the central bank on this volatility, these statistics are daily bearing on the period going from 03/10/2003 until 03/10/2021, the total number of observations used in the study is 4575 .

According to Table 1 in the appendices, regarding the position indicators, we can see that the average of the EUR/MAD exchange rate is 11.05825 and for the USD/MAD exchange rate is equal to 8.855326 . In addition, the median of the EUR/MAD exchange rate is 11.08085. Finally, the mode of bilateral exchange rates EUR/MAD and USD/MAD are respectively equal to 11.51050 and 10.30550 . Regarding the indicators of dispersion, in our case we will use the standard deviation as a mean to measure the dispersion, in fact the standard deviation of the EUR/MAD exchange rate is 0.197201 , the observations are on average, away from the center of the distribution. While the standard deviation of the USD/MAD exchange rate is 0.693366, the observations move away from the center of the distribution by 0.693366 in average. Finally, the shape indicators are measured by the following coefficients, first of all, the Skewness coefficient of the EUR/MAD exchange rate which is (-0.187826). This parameter is negative, signifying the left skewness of the distribution. As well as for the Skewness coefficient of the USD/MAD exchange rate which is equal to $(-0.092739)$, signifying the left skewness of the distribution. Next, the kurtosis coefficient of the EUR/MAD exchange rate is 3.501494. It is well above 3 and therefore our distribution is said to be less flat compared to a normal distribution (leptokurtic).

According to Figure 1 in the appendices, the shape of the graphs highlights the non-stationarity of the data since it seems to present a non-regular trend. The evolution of the variable studied fluctuates around several averages and a volatility that varies over time.

\subsection{Econometric Methodology}

ARCH (Autoregressive Conditional Heteroskedasticity) models are used to characterize and model time series. These models are often referred to ARCH models (Engle, 1982), although a variety of other acronyms are applied to particular model structures that have a similar basis. These are commonly applied in modeling financial time series, which include volatilities. It is a generalized ARCH model, because in this type of models the information about the conditional variance of errors is taken into account in the specification of the latter by including the values of lagged variances.

\subsection{Forecasting Performance}

In this paper, to identify the best forecasting model for the Moroccan dirham exchange rate, we used several measures such as the mean squared error (MSE), the mean absolute error (MAE), and the Theil inequality (TE).

- The Root Mean Square Error:

$$
R M S E \sqrt{\frac{\sum_{t=1}^{n} e_{t}^{2}}{n}}
$$

- The Mean Absolute Error :

$$
M A E=\frac{\sum_{t=1}^{n}\left|e_{t}\right|}{n}
$$

- Theil's inequality coefficient:

$$
T I=\frac{(\text { RMSE of the previsional model })}{(\text { RMSE of the actual model })}
$$

Thus, the lower the values of MAE, RMSE and IT or even closer to 0 , the better the model is considered to fit. 


\section{Results and Discussions}

This section is reserved for the estimation of the best model to this problem, as well as deducing the mathematical formula of the estimated model. While in the second place will be presented the analysis and comparison of the results with other empirical works, with the presentation of the main results of this study.

\subsection{Stationary Test and ARMA Model Selection}

In order to study the volatility of the bilateral exchange rate we will empirically examine the ARMA - GARCH model as well as its extensions (TGARCH, EGARCH and IGARCH). Thus, the approach that will be adopted for the final choice of the model will consist in first presenting the stationarity of the variables of the bilateral exchange rates EUR/MAD and USD/MAD with the help of the stationarity tests ADF and PP, and then proceeding secondly to the selection of the ARMA model, as well as the selection of the optimal GARCH model. The ADF and PP tests are parametric tests that allow us to determine whether a statistical time series is stationary or not. These tests are based on the estimation of an autoregressive process.

According Table 2 to this test, we find that the bilateral EUR/MAD and USD/MAD exchange rate variables are stationary in first difference, i.e. are integrated of order 1.

As can be seen in Table 3, Based on the automatic selection of ARMA models, we found that ARMA(1,0) is the model that have been retained for the variation of the bilateral exchange rates EUR/MAD and USD/MAD. After selecting the ARMA models, we will first estimate this selected model and then we will select the GARCH model in order to compare the different AR-GARCH models to capture the asymmetry of the exchange rate volatility. In the following we will try to present the results of the ARCH test in order to verify the effect and the existence of volatility.

As can be seen in Table 4, the probability values are equal to 0.00. These results of the ARCH LM test are considered significant at the 5\% level. Therefore, these results indicate that the null hypothesis $\mathrm{H}_{0}$ must be rejected, in other words, we reject the null hypothesis of homoscedasticity in favor of the alternative of conditional heteroscedasticity. This confirms the presence of an ARCH effect.

\subsection{ARCH Family Models Analysis and Comparisons}

To empirically assess the volatility of bilateral exchange rates in Morocco, we will study the volatility of the bilateral exchange rate using the results of the AIC and SIC selection criteria of the AR(1)-GARCH $(1,1)$ models and its extensions AR(1)-TGARCH(1,1), AR(1)-EGARCH(1,1) and AR(1)-IGARCH(1,1).

According to Table 5 in the appendices, the comparison of the different models retained above according to the AIC and SIC information criteria, which have the smallest values, leads us to choose the $\operatorname{AR}(1)-\operatorname{TGARCH}(1,1)$ process for modeling exchange rate volatility. A reading of the estimated model parameters of the EUR/MAD and USD/MAD bilateral exchange rates shows that all coefficients of the mean and variance equations are significantly different from zero. Moreover, they are statistically significant at the 5\% level and therefore allow us to say that there is an asymmetry phenomenon.

From Figure 2 in the appendices, we see that there is a high volatility of the bilateral exchange rates studied. By remaining within this framework, we conclude that the volatility of bilateral exchange rates is asymmetric. This presence of asymmetry leads us to address the problem of this asymmetry in order to verify whether central bank intervention on the exchange market is the main source of this asymmetry. In order to answer this question and to study the impact of central bank intervention on the volatility of the bilateral exchange rate, we will integrate two variables of this intervention (purchases and sales of currencies on the foreign exchange market) in the estimation of the AR(1)-TGARCH $(1,1)$ model (because the latter simply verifies the asymmetry condition). The equation of the model will be written mathematically as follows:

$$
\text { TGARCH }(1,1): h_{t}=\left\{\begin{array}{l}
\omega+\alpha_{1} \varepsilon_{t-1}^{2}+\beta h_{t-1}+a+b \\
\omega+\alpha_{2} \varepsilon_{t-1}^{2}+\beta h_{t-1}+a+b
\end{array}\right\}
$$

where $h_{t}$ is a conditional variance, $\omega$ is the mean, and $\alpha, \beta$ are the ARCH and GARCH terms, respectively, and the sum of these terms gives the information about the shocks to volatility. This asymmetric model allowed for an asymmetric response showing that negative shocks will result in higher volatility than positive shocks. Here is the estimation of the parameters of the selected model. "a" and " $b$ " are respectively the purchases and sales of currencies by the central bank on the foreign exchange market (interbank).

From Table 6 in the appendices, according to the estimation of the volatility of bilateral exchange rates according to the $\operatorname{AR}(1)-T G A R C H(1,1)$ model, we can see that the intervention of the central bank on the foreign exchange market has a negative impact $(a=-0.06 ; b=-0.04)$ on the volatility of the EUR/MAD exchange rate. While the estimate of the 
volatility of the USD/MAD exchange rate, was found that the intervention of the central bank on the foreign exchange market also has a negative impact $(a=-0.17 ; b=-0.11)$. Thus, these results are statistically significant at the $5 \%$ level (because the probability values of "a" and "b" are less than 5\%). Having determined the impact of central bank intervention on bilateral exchange rate volatility, we will now turn to the second point, studying the source of the asymmetry in exchange rate volatility. In fact, these estimates of the $\operatorname{AR}(1)-\mathrm{TGARCH}(1,1)$ model will be used to perform a test of equality of the two variables purchases and sales of currencies by identifying that purchases represent positive shocks while sales represent negative shocks, this test informs on the effect of these shocks on the volatility of the exchange rate. At this point, if the first question is verified, we can see that central bank intervention in the interbank market has no effect on the asymmetry of bilateral exchange rate volatility. On the other hand, if the last question is verified, we can ask ourselves about the level of effect of each variable on volatility. In this case, we can see that central bank intervention in the foreign exchange market is the source of this asymmetry.

From Table 7 in the appendices, the Wald test measures the effect of the buy and sell variables on the volatility of the EUR/MAD and USD/MAD exchange rates. Based on the AR(1)-TGARCH $(1,1)$ model, the results of this test of equality showed that both the buy and sell variables have a small probability of being equal for the bilateral exchange rates studied. This is because the chi-square probability is less than $5 \%$ for the EUR/MAD $(0.00)$ and USD/MAD $(0.00)$ exchange rates. Thus, these results imply that positive (buying) and negative (selling) shocks have different impacts on the volatility of the empirically analyzed bilateral exchange rates. Finally, we can see that central bank intervention has a direct effect on the asymmetry of exchange rate volatility.

\subsection{Forecasting Accuracy Comparisons}

From Table 8 in the appendices, according to the results obtained, we find that the best optimal model to predict the future evolution of the exchange rate of Moroccan dirham EUR / MAD and USD / MAD is the model AR (1) TGARCH $(1,1)$, while based on the distribution Student's-t. In addition, the forecasting performance of the estimated model to model volatility and make forecasts are based on the calculations of the mean square error (MSE), mean absolute error (MAE), and Theil Inequality (TI). Given that, the chosen model has the lowest values of RMSE, MAE and TI which are very close to 0 .

From Figure 4 in the appendices, we can see that the evolution of the EUR/MAD exchange rate has a controllable volatility in terms of forecasting while that of the USD/MAD bilateral exchange rate is almost zero. This result could be explained by the intervention of the central bank (monetary authorities) on the foreign exchange market, which consequently allows to control well this fluctuation on this type of market studied. By analyzing the results of this empirical study, we could clearly show that the asymmetry of the volatility of the bilateral exchange rate in Morocco is verified thanks to the estimated parametric model AR (1)-TGARCH $(1,1)$ which indicated that the data of the exchange rates present signs of asymmetrical response. Moreover, this asymmetry is explained by the intervention of the central bank and the Moroccan monetary authorities on the exchange market. Thus, positive (buying) and negative (selling) shocks have several types of effects on the volatility of the bilateral USD/MAD and EUR/MAD exchange rates. Therefore, the active participation of the central bank in the Moroccan foreign exchange market remains the only source of the asymmetry in the volatility of the bilateral exchange rates studied statistically.

Comparing the results of other empirical studies with our analysis and reflection, we find that most of the empirical studies have shown the same results that assert the presence of asymmetry on exchange rate volatility. The work of Atoi and Friday (2017), is an example, they found the presence of asymmetric effect on the volatility of the Nigerian exchange rate using the Asymmetric Volatility Model. In addition, Narsoo (2015) empirically analyzed the volatility of the US Dollar/Mauritian Rupee (USD/MUR) exchange rate using different GARCH type models. His study showed that there is evidence of the presence of volatility clustering and asymmetric effect on exchange rate volatility. As Pelinescu (2014) applied the different ARCH-GARCH models on the volatility of the Romanian exchange rate against the euro for a daily database, finally concluding that the volatility of the exchange rate is asymmetric, this research leads several authors to question the source of this asymmetry, stating that the intervention of the central bank on the exchange market is the only source of the asymmetry of the exchange rate volatility. By the end, our empirical study found that the asymmetry of the volatility of the exchange rate is due to and linked directly to these interventions.

\section{Conclusion}

The main objective of this paper was to model the volatility of the exchange rate of the Moroccan dirham (EUR/MAD and USD/MAD) and to determine the most appropriate model for modeling the fluctuations of the Moroccan dirham while determining the sources of asymmetry of this volatility. This study has shown that our series is characterized by the phenomenon of volatility, asymmetric specifications, and the presence of excessive kurtosis. Moreover, the results obtained have allowed us to confirm the null hypothesis which puts forward the idea that asymmetric non-linear models are the most appropriate to answer our problem. Thus, the central bank of several countries intervenes on the exchange market to reduce this volatility despite the transition to a floating exchange rate. And to achieve its objective, the central 
bank generally participates in the sale of currencies in case of a depreciation of the national currency and vice versa.

Following these considerations, our study was interested firstly in studying the volatility of bilateral exchange rates in Morocco from which we found that the volatility of bilateral exchange rates is asymmetric according to the $\operatorname{AR}(1)$-TGARCH(1,1) model, this conclusion allowed us to study the relationship between the intervention of the central bank on the exchange market and the asymmetry of the volatility of the exchange rate. Referring to previous works that have affirmed the existence of this relationship in most countries using different empirical GARCH models, the market reaction is greater when the exchange rate falls than if it increases.

Therefore, the sales of foreign exchange reserves by central banks accompany a fall in the exchange rate, which means that the market response to shocks is asymmetric. Finally, the sale of currencies by central banks increases the volatility of the exchange rate. This indicates that this intervention can be more repressive than profitable to market volatility.

\section{References}

Abdalla, S., \& Zakaria, S. (2012). Modelling Exchange Rate Volatility Using GARCH Models: Empirical Evidence from Arab Countries. International Journal of Economics and Finance, 4(3), 216. https://doi.org/10.5539/ijef.v4n3p216

Adeoye, B. W., \& Akinwande, A. (2011). Exchange Rate Volatility in Nigeria : Consistency, Persistency \& Severity Analyses. Journal of Applied Statistics, 2(2), 29-49.

Adi, A. (2017). Returns Effect, Shocks and Volatility Transmission between Foreign Exchange-Stock Markets in Nigeria. Academic Journal of Economic Studies, 3(1), 29-38.

Adi, A. (2019). Modeling Exchange Rate Return Volatility of RMB/USD Using GARCH Family Models. Journal of Chinese Economic and Business Studies, 17(2), 169-87. https://doi.org/10.1080/14765284.2019.1600933

Ajao, M., \& Olushola, E. I. (2021). The Determinants of Real Exchange Rate Volatility in Nigeria. Academic Journal of Interdisciplinary Studies.

Ali, G. (2013). EGARCH, GJR-GARCH, TGARCH, AVGARCH, NGARCH, IGARCH and APARCH Models for Pathogens at Marine Recreational Sites. Journal of Statistical and Econometric Methods, 2(3).

Alom, F. (2016). The Asymmetry and Persistency of Shocks in Malaysian. Exchange Rate Volatility, 53(December 1): 227-238.

Atoi, N., \& Victor, N. (2017). Asymmetric Analysis of Exchange Rates Volatility: Evidence from Emerging Economy. IOSR Journal of Business and Management, 19(1), 82-90. https://doi.org/10.9790/487X-1901048290

Bai, J., \& Pierre, P. (2003). Computation and Analysis of Multiple Structural Change Models. Journal of Applied Econometrics, 18(1), 1-22. https://doi.org/10.1002/jae.659

Baillie, R., \& Bollerslev, T. (1989). Common Stochastic Trends in a System of Exchange Rates. The Journal of Finance, 44(1), 167-81. https://doi.org/10.1111/j.1540-6261.1989.tb02410.x

Baillie, R., Bollerslev, T., \& Hans, O. (1996). Fractionally Integrated Generalized Autoregressive Conditional Heteroskedasticity. Journal of Econometrics, 74(1), 3-30. https://doi.org/10.1016/S0304-4076(95)01749-6

Baillie, R., \& William, P. (1997). Why Do Central Banks Intervene? Journal of International Money and Finance, 16(6), 909-19. https://doi.org/10.1016/S0261-5606(97)00012-0

Bala, D. A., \& Joseph, O. (2013). Exchange-Rates Volatility in Nigeria: Application of GARCH Models with Exogenous Break. Journal of Applied Statistics, 4(1), 28.

Bollerslev, T., \& Engle, R. (1993). Common Persistence in Conditional Variances. Econometrica, 61(1), 167-86. https://doi.org/10.2307/2951782

Engle, R. (1982). Autoregressive Conditional Heteroscedasticity with Estimates of the Variance of United Kingdom Inflation. Econometrica, 50(4), 987-1007. https://doi.org/10.2307/1912773

Epaphra, M. (2017). Modeling Exchange Rate Volatility: Application of the GARCH and EGARCH Models. Journal of Mathematical Finance, 121-143. https://doi.org/10.4236/jmf.2017.71007

Hassan, S. (2012). Persistence And Asymmetry In Exchange Rate Volatility. International Business \& Economics Research Journal (IBER), 11, 971. https://doi.org/10.19030/iber.v11i9.7180

Isenah, G., \& Olusanya, E. (2016). Empirical Model for Forecasting Exchange Rate Dynamics: The GO-GARCH Approach. Journal of Applied Statistics, 7(1), 179-208.

Li, Y., Pierre, P., \& Jiawen, X. (2017). Modelling Exchange Rate Volatility with Random Level Shifts. Applied Economics, 49(26), 2579-89. https://doi.org/10.1080/00036846.2016.1243214 
McKenzie, M. (2002). The Economics of Exchange Rate Volatility Asymmetry. International Journal of Finance \& Economics, 7(3), 247-60. https://doi.org/10.1002/ijfe.189

Mia, S., \& Siddikur, R. (2019). Evaluating the Forecast Accuracy of Exchange Rate Volatility in Bangladesh Using ARCH Family of Models. American Journal of Mathematics and Statistics, 9(5), 183-90.

Mustapha, D. (2020). Volatility and Long Memory Modeling of Exchange Rate Case of Algerian Interbank Market. International Journal of Economics, Finance and Management Sciences, 8(4), 128. https://doi.org/10.11648/j.ijefm.20200804.11

Narsoo, J. (2015). Forecasting USD/MUR Exchange Rate Dynamics: An Application of Asymmetric Volatility Models. International Journal of Statistics and Applications, 5(5), 247-56.

Oyinlola, M. (2018). Modelling Volatility Persistence and Asymmetry of Naira-Dollar Exchange Rate. Journal of Applied Statistics, 9(1), 141-65.

Rahman, M., \& Zahangir, A. (2012). Modelling Volatility of the BDT/USD Exchange Rate with GARCH Model. International Journal of Economics and Finance, 4(October 15), 193-204. https://doi.org/10.5539/ijef.v4n11p193

Zhang, Y., Ting, Y., Ling, Y. H., \& Ronald, R. (2019). Volatility Forecasting of Crude Oil Market: Can the Regime Switching GARCH Model Beat the Single-Regime GARCH Models? International Review of Economics \& Finance , 59C, 302-17. https://doi.org/10.1016/j.iref.2018.09.006

\section{Appendices:}

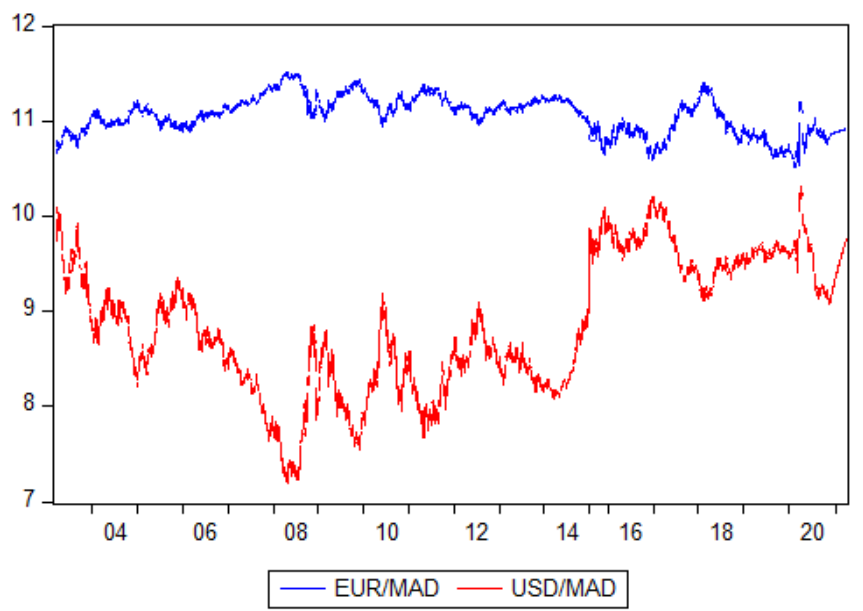

Figure 1. Graphical representation of the EUR/MAD and USD/MAD exchange rates

Source: Authors, from EViews 10 software

Table 1. Descriptive statistics of the bilateral EUR/MAD and USD/MAD exchange rates

\begin{tabular}{|l|c|c|}
\hline & EUR/MAD & USD/MAD \\
\hline Average & 11.05825 & 8.855326 \\
\hline Median & 11.08085 & 8.796050 \\
\hline Mode & 11.51050 & 10.30550 \\
\hline Standard deviation & 0.197201 & 0.693366 \\
\hline Skewness coefficient & -0.187826 & -0.092739 \\
\hline Coefficient of Kurtosis & 3.501494 & 3.090259 \\
\hline Jarque-Bera & 74.25573 & 164.2887 \\
\hline Probability & 0.000000 & 0.000000 \\
\hline Observations & 4575 & 4575 \\
\hline
\end{tabular}

Source: Authors, from EViews 10 software 
Table 2. ADF and PP stationarity tests

\begin{tabular}{|l|c|c|c|c|c|}
\hline & \multicolumn{2}{|c|}{ ADF (\% 5) } & \multicolumn{2}{c|}{ Phillips-Perron (\% 5) } & \\
\hline Variable & $\begin{array}{c}\text { Niveau } \\
\text { (Intercept) }\end{array}$ & $\begin{array}{c}\text { 1ère. Différence } \\
\text { (Intercept) }\end{array}$ & $\begin{array}{c}\text { Niveau } \\
\text { (Intercept) }\end{array}$ & $\begin{array}{c}\text { 1ère. Différence } \\
\text { (Intercept) }\end{array}$ & Niveau \\
\hline EUR/MAD & -2.604057 & -78.82687 & -2.616869 & -79.92359 & I (1) \\
& $(-3.410788)$ & $(-3.410788)$ & $(-3.410787)$ & $(-3.410788)$ & \\
\hline \multirow{2}{*}{ USD/MAD } & -2.844759 & -68.95588 & -2.834902 & -68.94847 & I (1) \\
& $(-3.410787)$ & $(-3.410788)$ & $(-3.410787)$ & $(-3.410788)$ & \\
\hline
\end{tabular}

Source: Authors, from EViews 10 software

Table 3. Results of the estimations of the ARMA(1,0) model

\begin{tabular}{|c|c|c|}
\hline & EUR/MAD & USD/MAD \\
\hline Constante & 0.00 & 0.00 \\
(P-value) & $(0.00)$ & $(0.00)$ \\
\hline AR(1) & 0.58 & 0.49 \\
(P-value) & $(0.00)$ & $(0.00)$ \\
\hline
\end{tabular}

Source: Authors, from EViews 10 software

Table 4. Results of the Lagrange Multiplier ARCH test

\begin{tabular}{|l|c|c|}
\hline & EUR/MAD & USD/MAD \\
\hline F-statistic & 14.31 & 38.55 \\
(Prob. F(1,52)) & $(0.00)$ & $(0.00)$ \\
\hline Obs*R-squared & 44.36 & 45.19 \\
(Prob. Chi-Square(1)) & $(0.00)$ & $(0.00)$ \\
\hline
\end{tabular}

Source: Authors, from EViews 10 software

Table 5. Results of parameter estimates of the GARCH $(p, q)$ models and selection of the optimal model

\begin{tabular}{|c|c|c|c|c|c|c|c|}
\hline & & & EUR/MAD & & & USD/MAD & \\
\hline \multirow{8}{*}{ AR(1)-GARCH(1,1) } & & $* \mathrm{SD}$ & $* *$ GED & $* * * \mathrm{JSU}$ & SD & GED & JSU \\
\hline & $\mathrm{AR}(1)$ & -0.174383 & -0.171731 & -0.171718 & 0.006244 & -0.025343 & -0.029345 \\
\hline & $\omega$ & $-2.06 \mathrm{E}-08$ & $-7.54 \mathrm{E}-09$ & $-8.90 \mathrm{E}-09$ & $-9.73 \mathrm{E}-07$ & $2.75 \mathrm{E}-07$ & $4.29 \mathrm{E}-07$ \\
\hline & $\alpha$ & 0.106370 & 0.109162 & 0.107246 & 0.052970 & 0.052034 & 0.051305 \\
\hline & $\beta$ & 0.905857 & 0.902483 & 0.904334 & 0.953758 & 0.950066 & 0.951990 \\
\hline & $\gamma$ & - & - & - & - & - & - \\
\hline & AIC & -5.184086 & -5.224477 & -5.217696 & -3.729158 & -3.830528 & -3.807279 \\
\hline & SIC & -5.178462 & -5.217448 & -5.210667 & -3.723534 & -3.823498 & -3.800250 \\
\hline \multirow{7}{*}{ AR(1)-TGARCH $(1,1)$} & $\mathrm{AR}(1)$ & -0.174503 & -0.172088 & -0.172123 & -0.000476 & -0.025194 & -0.029898 \\
\hline & $\omega$ & $-1.38 \mathrm{E}-08$ & $-6.15 \mathrm{E}-10$ & $-1.99 \mathrm{E}-09$ & $-1.61 \mathrm{E}-06$ & $3.34 \mathrm{E}-07$ & $2.41 \mathrm{E}-07$ \\
\hline & $\alpha$ & 0.092140 & 0.094180 & 0.092594 & 0.074677 & 0.050443 & 0.057426 \\
\hline & $\beta$ & -0.027941 & 0.028681 & 0.028473 & -0.044041 & 0.003295 & -0.012791 \\
\hline & $\gamma$ & 0.906158 & 0.903106 & 0.904769 & 0.954582 & 0.949960 & 0.952388 \\
\hline & AIC & -5.204667 & -5.244797 & -5.218012 & -3.748175 & -3.840121 & -3.807297 \\
\hline & SIC & -5.177638 & -5.216361 & -5.209577 & -3.731145 & -3.821685 & -3.798861 \\
\hline \multirow{12}{*}{ AR(1)-EGARCH(1,1) } & $\mathrm{AR}(1)$ & -0.17223 & -0.167594 & -0.168518 & 0.001353 & -0.022903 & -0.028572 \\
\hline & $\omega$ & -0.167679 & -0.176679 & -0.177613 & -0.086082 & -0.093715 & -0.094125 \\
\hline & $\alpha$ & 0.196885 & 0.197432 & 0.197161 & 0.104405 & 0.102852 & 0.102563 \\
\hline & $\beta$ & -0.029850 & -0.029455 & -0.028537 & 0.998833 & 0.997932 & 0.997639 \\
\hline & $\gamma$ & 0.997931 & 0.996963 & 0.996794 & 0.886931 & 0.888464 & 0.886484 \\
\hline & AIC & -5.191842 & -5.233232 & -5.225544 & -3.732355 & -3.834032 & -3.811033 \\
\hline & SIC & -5.184813 & -5.224797 & -5.217109 & -3.726731 & -3.827003 & -3.804004 \\
\hline & $\mathrm{AR}(1)$ & -0.177341 & -0.172871 & -0.173103 & 0.007107 & -0.025346 & -0.029323 \\
\hline & $\omega$ & 0.085973 & 0.090146 & 0.087670 & 0.042908 & 0.047102 & 0.043738 \\
\hline & $\alpha$ & 0.914027 & 0.909854 & 0.912330 & 0.957092 & 0.952898 & 0.956262 \\
\hline & $\beta$ & - & - & - & - & - & - \\
\hline & $\gamma$ & - & - & - & - & - & - \\
\hline
\end{tabular}




\begin{tabular}{|c|c|c|c|c|c|c|c|}
\hline AR(1)-IGARCH(1,1) & AIC & -5.177629 & -5.221589 & -5.214335 & -3.723058 & -3.830766 & -3.806414 \\
\cline { 2 - 8 } & SIC & -5.174817 & -5.217372 & -5.210117 & & & \\
& & & & & & -3.720246 & -3.826549 \\
& & & & & -3.802197 \\
\hline
\end{tabular}

* Student's t-distribution * * Generalised Error Distribution (GED) $\quad * \quad * \quad *$ Johnson's SU (JSU)

Source: Authors, from EViews 10 software

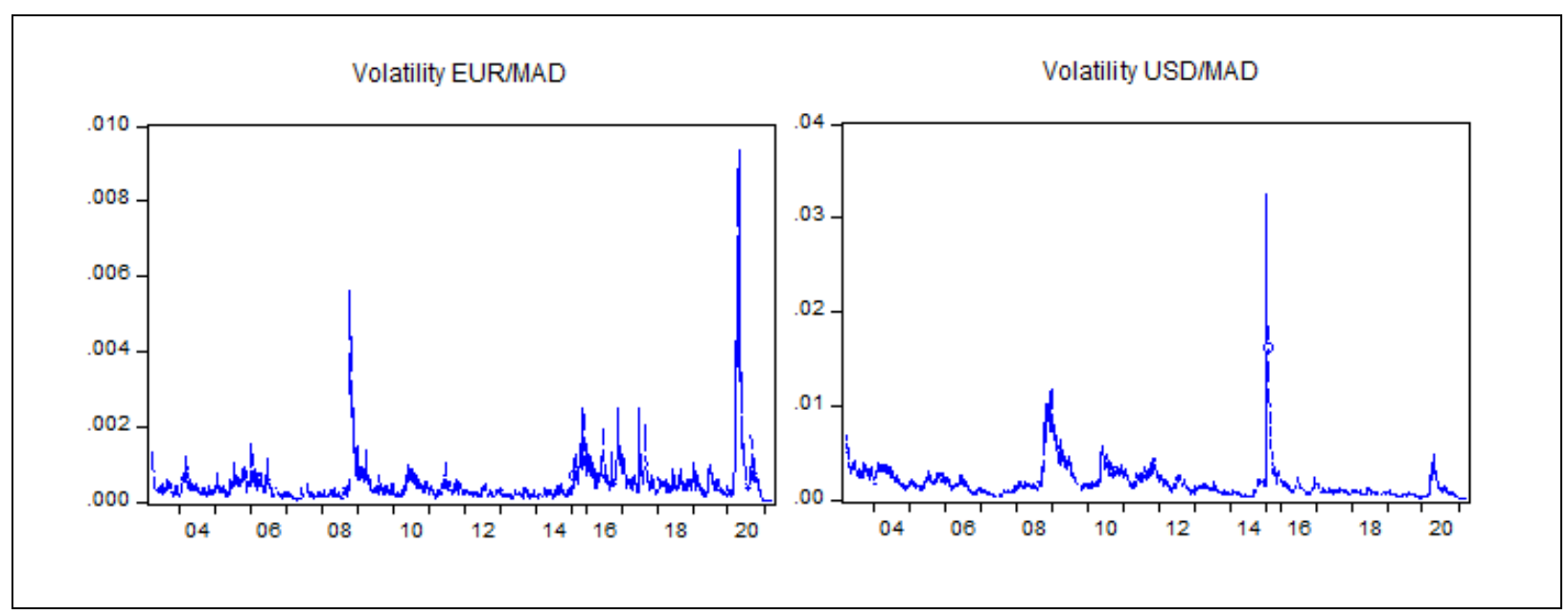

Figure 2. Volatility of bilateral EUR/MAD and USD/MAD exchange rates

Source: Authors, from EViews 10 software

Table 6. Results of the AR(1)-TGARCH(1,1) estimation of bilateral exchange rates

\begin{tabular}{|c|c|c|}
\hline & EUR/MAD & USD/MAD \\
\hline Variable & Coefficient & Coefficient \\
& (P-value) & 0.027801 \\
\hline $\mathrm{AR}(1)$ & 0.195010 & $(0.00)$ \\
\hline$\omega$ & $(0.00)$ & $5.00 \mathrm{E}-08$ \\
& $1.74 \mathrm{E}-06$ & $(0.00)$ \\
\hline$\alpha_{1} \varepsilon_{t-1}^{2}$ & $(0.00)$ & 0.055428 \\
$\alpha_{2} \varepsilon_{t-1}^{2}$ & 0.046057 & $(0.00)$ \\
\hline$\beta h_{t-1}$ & $(0.00)$ & -0.025434 \\
& -0.027955 & $(0.00)$ \\
\hline$a$ (achats) & $(0.00)$ & 0.978053 \\
& 0.939983 & $(0.00)$ \\
\hline$b$ (ventes) & $(0.00)$ & -0.17 \\
& -0.06 & $(0.00)$ \\
\hline
\end{tabular}

Source: Authors, from EViews 10 software

Table 7. Results of the Wald test of equality

\begin{tabular}{|c|c|c|}
\hline & EUR/MAD & USD/MAD \\
\hline F-statistic & 7.46 & 2.39 \\
(Prob. F(1,10)) & $(0.00)$ & $(0.00)$ \\
\hline Obs*R-squared & 7.76 & 3.46 \\
(Prob. Chi-Square(1)) & $(0.00)$ & $(0.00)$ \\
\hline
\end{tabular}

Source: Authors, from EViews 10 software 
Table 8. Error Statistics value for the forecasting performance

\begin{tabular}{|c|c|c|c|}
\hline \multicolumn{2}{|c|}{} & EUR/MAD & USD/MAD \\
\hline \multirow{3}{*}{ AR(1)-GARCH(1,1) } & $*$ RMSE & 0.050670 & 0.041799 \\
\cline { 2 - 4 } & $* *$ MAE & 0.024712 & 0.029503 \\
\cline { 2 - 4 } & $* * *$ TI & 0.043622 & 0.075110 \\
\hline \multirow{3}{*}{ AR(1)-TGARCH(1,1) optimal model } & RMSE & 0.010670 & 0.033786 \\
\cline { 2 - 4 } & MAE & 0.014712 & 0.028505 \\
\cline { 2 - 4 } & TI & 0.043371 & 0.075252 \\
\hline \multirow{2}{*}{ AR(1)-EGARCH(1,1) } & RMSE & 0.020669 & 0.041798 \\
\cline { 2 - 4 } & MAE & 0.014712 & 0.029506 \\
\cline { 2 - 4 } & TI & 0.846549 & 0.077957 \\
\hline \multirow{2}{*}{ AR(1)-IGARCH(1,1) } & RMSE & 0.014712 & 0.045797 \\
\cline { 2 - 4 } & MAE & 0.842821 & 0.075108 \\
\hline
\end{tabular}

* Root Mean Squared Error $* *$ Mean Absolute Error $* * *$ Theil Inequality Coefficient

Source: Authors, from EViews 10 software
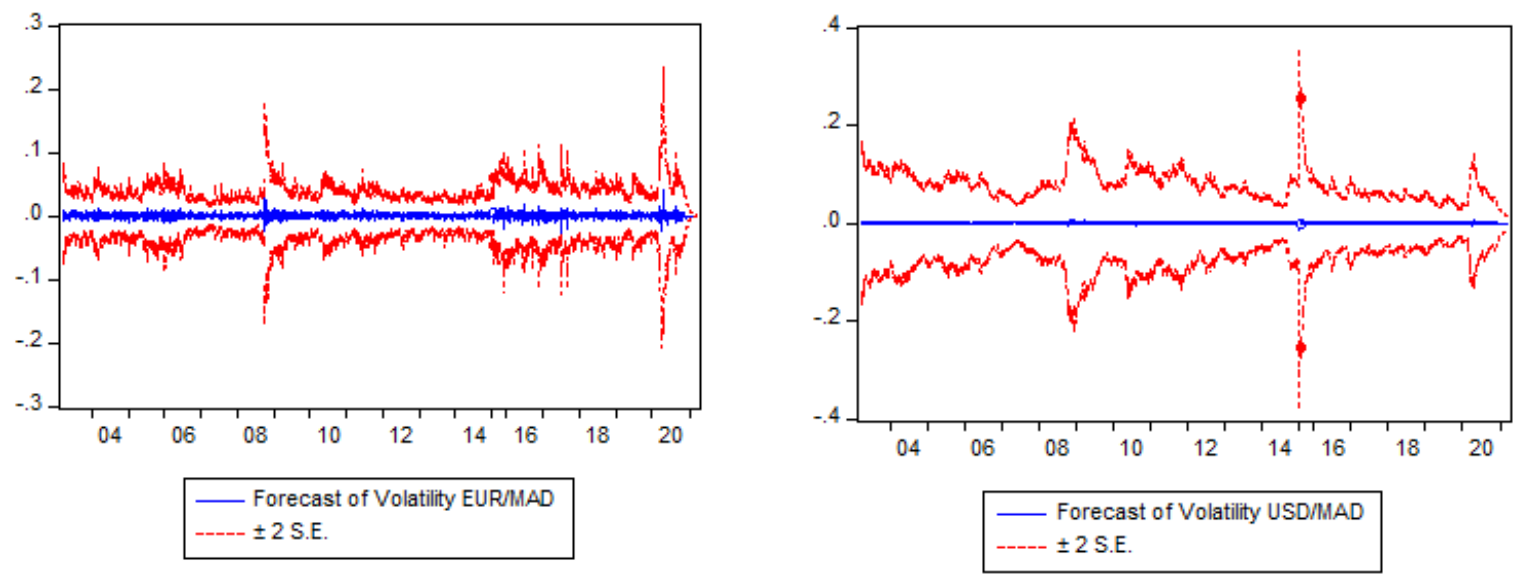

Figure 3. Forecast volatility of bilateral EUR/MAD and USD/MAD exchange rates

Source: Authors, from EViews 10 software

\section{Copyrights}

Copyright for this article is retained by the author(s), with first publication rights granted to the journal.

This is an open-access article distributed under the terms and conditions of the Creative Commons Attribution license which permits unrestricted use, distribution, and reproduction in any medium, provided the original work is properly cited. 